\section{Shoulder Injuries in Sports}

Philip J. Marone

London, UK: Martin Dunitz, 1992, $£ 39.95,250 \times 193 \mathrm{~mm}, 178 \mathrm{pp}$

Disorders of the shoulder have become one of the new expanding fields of orthopaedics, with arthroscopy contributing greatly to our understanding. There is a need for a book dealing with sporting injuries in this fascinating field. The author is an American orthopaedic surgeon from Philadelphia, who cares for the Phillies baseball team. This text is relatively small and affordable, with 178 pages and I set out to read it enthusiastically.

The book is divided along standard lines with anatomy and biomechanics preceding chapters on examination and investigation. There is an overview of shoulder injuries before separate chapters covering the anatomical areas where injuries occur. Finally, there is a chapter devoted to rehabilitation.

The anatomy is far too basic and overlaps with the chapter on biomechanics, each chapter dealing with both topics. Simple biomechanics of throwing are found in a third chapter. The important glenohumeral ligaments are ignored until the chapter on the glenohumeral joint, and even then poorly done. The rotator cuff is inadequately described. Throwing other than baseball pitching is barely mentioned and the line drawings used are poor.

The section on history and examination has only one page of text. The important history of shoulder injuries is neglected. I was surprised to read that we should be examining pelvic organs and kidneys in sportsmen with shoulder problems, and yet the neck, a potent source of shoulder pain is not mentioned in this chapter. No distinction is made between active and passive ranges of movement, and painful arcs and apprehension tests

\section{Shoulder injuries}

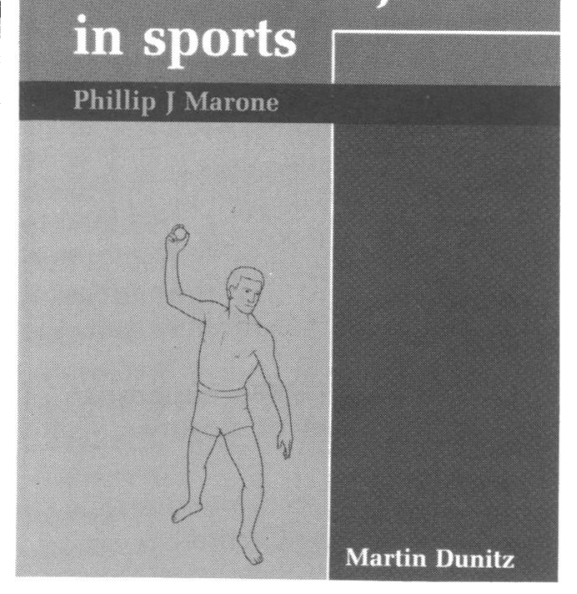

are ignored. The picture illustrating the testing of supraspinatus strength does not show the arm above the elbow.

The section on investigation wastes space by describing the mechanics of plain radiography which may be of use to a radiographer. It assumes availability of a magnetic resonance imaging scanner, barely mentions arthrography and computed tomographic scanning, but devotes three pages to figures of electromyographic studies with no explanations. Arthroscopy, so important, merits less than half that.

I do not really see the need for the 'overview' chapter, which not only covers the same subjects as the chapters devoted to the region itself, but splits the information. The injuries chapters are largely relevant to baseball, other sports are hardly mentioned. The text dealing with injuries is reasonable but by no means comprehensive. The author recommends the use of 6 days of prednisolone starting at $32 \mathrm{mg} \mathrm{day}^{-1}$ for a shoulder 'sprain', quite astonishing

This book fails. It is incomplete, inaccurate, anecdotal, and needs to be rewritten and reillustrated.

\section{R. Hackney MB, Dip Sports Med}

\section{Practical Joint Assessment: A Sports Medicine Manual} Anne Hartley

St. Louis, USA: Mosby Year Book, 1990, £35.50, 714 pp

Written originally as a manual for Canadian Athletic Therapy students, it is a comprehensive guide to examination, specifically of the muskuloskeletal system of the sportsperson.

The author is a member of the Canadian Athletic Therapist Association (CATA), and while writing the text, was a Lecturer on the Sports Injury Management Programme in athletic therapy at Sheridan College in Oakville, Ontario.

The book is divided into two sections, the upper and lower quadrants. Preceding these is an introductory section covering general objective assessment guidelines and history taking.

The main body of the book, examination of the upper and lower quadrants, gives an anatomical and functional outline of each joint followed by assessment guidelines.

These guidelines specifically involve a detailed description of the history liked to see even more on the functional adaptation and exercise-related

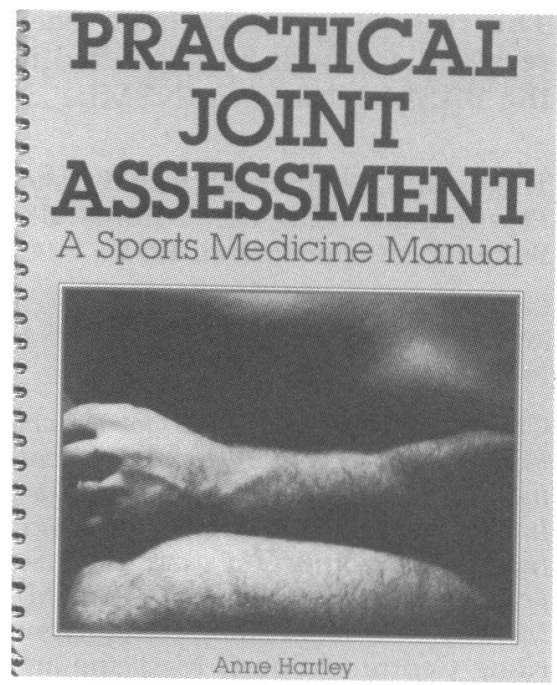

changes in tendon and ligament, more on the lines of McNeill Alexander's work in relating visco-elastic energy storage in the collagenous elements with actual running performance. For example, he has computed that at speeds of around $300 \mathrm{~m} \mathrm{~min}^{-1}$ a runner may store and regain $50 \%$ of the energy at each stride. Also, Cavagna has indicated that without visco-elastic assistance humans should not be able to sprint faster than some $0.7 \mathrm{~m} \mathrm{~s}^{-1}$. That is the kind of practical relation of structure to function that I would look upon, in such a chapter, as the icing on the cake!

Part 3 contains eight chapters on mechanisms of adaptation in strength and power training, starting with an excellent review of molecular and cellular aspects of adaptation in muscle by Geoffrey Goldspink, and going on through hypertrophy or hyperplasia (coming down firmly on the side of the former) by MacDougal, neural adaptations by Tesch, another look at connective tissue by Stone which is good on bone, and ending, interestingly enough, with Fleck writing on the cardiovascular responses to strength training. Part 4 deals with special problems, such as clinical aspects and ageing, and also the use of electrical stimulation in strength and power training. In this last aspect I am surprised that there is no mention of the possible moral aspects of such 'nerve doping' in relation to sport, indeed I found it somewhat chilling that the ethical side was not mentioned. The final part relates to specific training for weightlifting, power events and, interestingly, bodybuilding, by Tesch.

Altogether, this book is a must for all interested in the scientific aspects of strength and power. I recommend it very highly indeed.

Craig Sharp PhD, MRCVS 


\section{Book reviews: Erratum}

Due to a typesetting error in the September issue, parts of the following two reviews were mismatched. We apologize for any inconvenience caused, in particular to the reviewers, Craig Sharp and Carey Jones, and the book authors.

\section{Practical Joint Assessment: A Sports Medicine Mannual Anne Hartley}

St. Louis, USA: Mosby Year Book, 1990, £35.50, 714 pp

Written originally as a manual for Canadian Athletic Therapy students, it is a comprehensive guide to examination, specifically of the muskuloskeletal system of the sportsperson.

The author is a member of the Canadian Athletic Therapist Association (CATA), and while writing the text, was a Lecturer on the Sports Injury Management Programme in athletic therapy at Sheridan College in Oakville, Ontario.

The book is divided into two sections, the upper and lower quadrants. Preceding these is an introductory section covering general objective assessment guidelines and history taking.

The main body of the book, examination of the upper and lower quadrants, gives an anatomical and functional outline of each joint followed by assessment guidelines.

These guidelines specifically involve a detailed description of the history and related aetiology of both common and uncommon sporting injuries to the musculoskeletal system. A variety of injuries specific to particular sports are covered. The objective guidelines give a comprehensive coverage of examination techniques in a logical

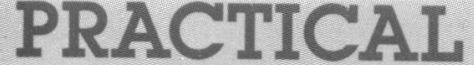
JOINT ASSESSMENT A Sports Medicine Manual

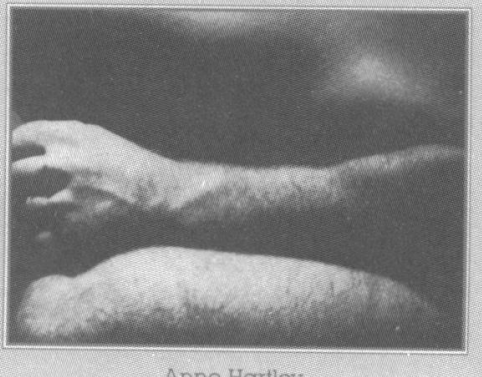

sequence. The possible interpretations of such findings are discussed on the facing page.

The author has avoided being dogmatic, by including a 'Smörgasbord' of assessment techniques combining many schools of thought from Cyriax and Maitland, to Elvey.

The assessment techniques are backed up by accurate line drawings and the sections on the shoulder joint and foot and ankle will be of particular use to the professional practising in sports medicine.

The reader will note that, being a North American text, a lot of the aetiology is based upon sports native to this region but with a minimal amount of imagination, this can be related to most sports.

Aimed specifically at physiotherapists, this book would prove to be an invaluable aid not only to this profession but also to novice doctors practising in Sports Medicine, where a logical guide to examination and assessment is essential.

\section{Carey Jones MCSP SRP}

\section{Strength and Power in Sport \\ P. V. Komi, ed.}

Oxford, UK: Blackwell Scientific Publications, 1992: 404 pp, £39.50

Apart from body composition and flexibility, virtually all of the purely physical side of sports training is directed at either endurance in its various forms, or strength and power, with power of course encompassing speed. This volume on strength and power, together with its companion 'Endurance in Sport' are exactly what many of us in the field have been waiting for. We now have two major works at the very core of sports physiology.

Thirty contributors write in five parts, of which the first consists of four pages of definitions. Part 2, on the biological basis for strength and power forms virtually half the book, with 13 chapters ranging from mechanical muscle models by Huijing, through the stretch-shortening cycle by Komi, muscle architecture and performance by Roy and Edgerton, the contractile performance of muscle fibres by Edman to hormonal mechanisms by Kraemer. Also in this section I am especially pleased to see a good chapter by Zernicke and Loitz on exercise-related adaptations to connective tissue, although I would have liked to see even more on the functional adaptation and exercise-related changes in tendon and ligament, more

\section{STRENGTH AND POWER IN SPORT IMTLD в P. V. ком!}
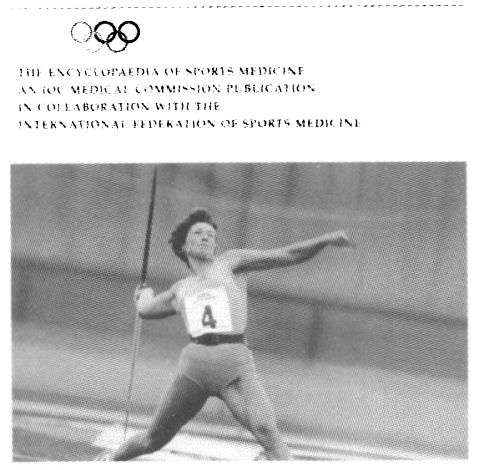

on the lines of McNeill Alexander's work in relating visco-elastic energy storage in the collagenous elements with actual running performance. For example, he has computed that at speeds of around $300 \mathrm{~m} \mathrm{~min}^{-1}$ a runner may store and regain $50 \%$ of the energy at each stride. Also, Cavagna has indicated that without visco-elastic assistance humans should not be able to sprint faster than some $0.7 \mathrm{~m} \mathrm{~s}^{-1}$. That is the kind of practical relation of structure to function that I would look upon, in such a chapter, as the icing on the cake!

Part 3 contains eight chapters on mechanisms of adaptation in strength and power training, starting with an excellent review of molecular and cellular aspects of adaptation in muscle by Geoffrey Goldspink, and going on through hypertrophy or hyperplasia (coming down firmly on the side of the former) by MacDougal, neural adaptations by Tesch, another look at connective tissue by Stone which is good on bone, and ending, interestingly enough, with Fleck writing on the cardiovascular responses to strength training. Part 4 deals with special problems, such as clinical aspects and ageing, and also the use of electrical stimulation in strength and power training. In this last aspect I am surprised that there is no mention of the possible moral aspects of such 'nerve doping' in relation to sport, indeed I found it somewhat chilling that the ethical side was not mentioned. The final part relates to specific training for weightlifting, power events and, interestingly, bodybuilding, by Tesch.

Altogether, this book is a must for all interested in the scientific aspects of strength and power. I recommend it very highly indeed.

Craig Sharp BVMS, FIBiol 